\title{
Erratum
}

\section{Stereoselective Synthesis of Stagonolide G from D-Mannitol}

Chebolu Naga Sesha Sai Pavan Kumar, Mettu Ravinder, Singam Naveen Kumar, Vaidya Jayathirtha Rao* Synthesis 2011, 451.

The structure for the synthesized stagonolide $\mathrm{G}$ has been revised according to the structure given in Org. Lett. 2010, 12, 5752. The final product in Scheme 4 is thus revised as per the new data available from the reference cited above.

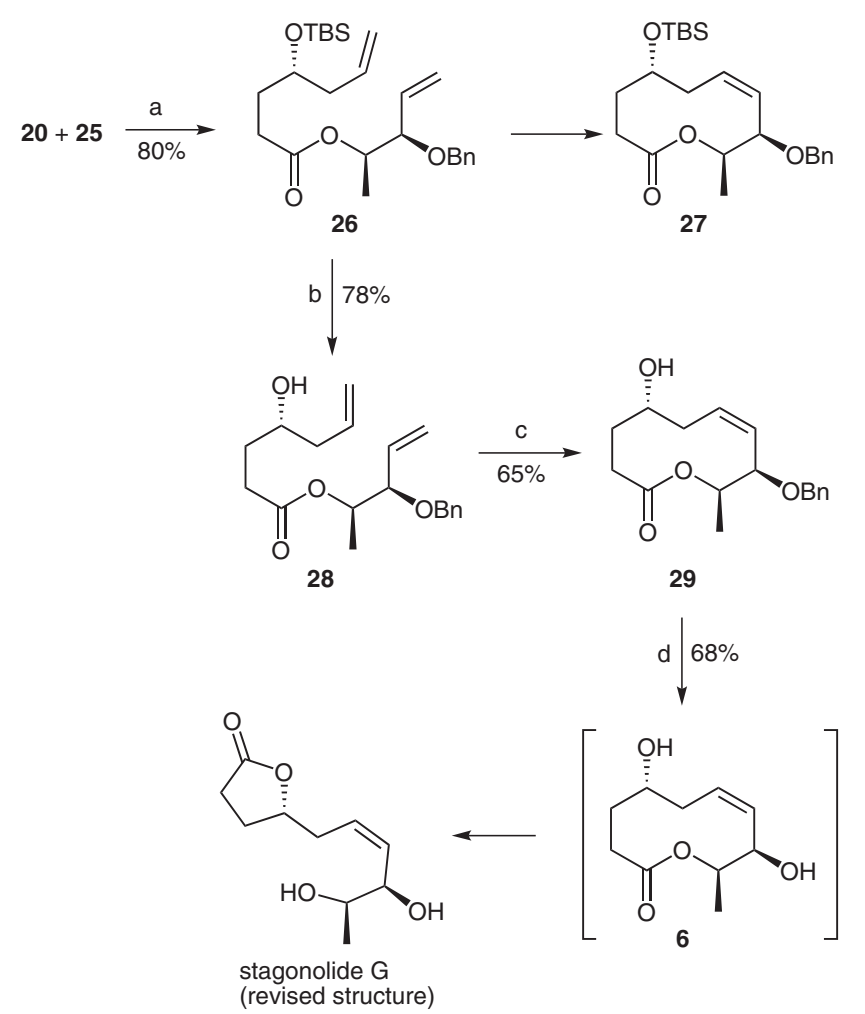

Scheme 4 Reagents and conditions: (a) 2,4,6-trichlorobenzoyl chloride, $\mathrm{Et}_{3} \mathrm{~N}$, anhyd THF, r.t., 2 h, DMAP, toluene, r.t.; (b) HF-pyridine, anhyd THF, $0{ }^{\circ} \mathrm{C} \rightarrow$ r.t.; (c) Grubbs II catalyst, anhyd $\mathrm{CH}_{2} \mathrm{Cl}_{2}$, reflux; (d) $\mathrm{Na}$, liq $\mathrm{NH}_{3}$, anhyd THF, $-78^{\circ} \mathrm{C}$

\section{Reference}

Angulo-Pachón, C. A.; Díaz-Oltra, S.; Murga, J.; Carda, M.; Alberto Marco, J. Org. Lett. 2010, 12, 5752. 